\title{
O PROGRAMA DE APOIO AO ESTUDANTE QUILOMBOLA (PAEQUI) COMO POLÍTICA DE PERMANÊNCIA NUMA UNIVERSIDADE DA AMAZÔNIA (UNIFESSPA-PA)
}

\author{
Maria Cristina Macedo Alencar ${ }^{1}$ \\ Karla Leandro Rascke ${ }^{2}$ \\ Jheyciele Naira dos Santos ${ }^{3}$
}

\begin{abstract}
Resumo: O trabalho foca a experiência de realização do Programa de Apoio ao Estudante Quilombola (PAEQUI), que constitui uma política preocupada com a permanência de estudantes quilombolas ingressantes na Unifesspa via Processo Seletivo Específico Indígena e Quilombola (PSIQ). O estudo foi realizado com a análise de fontes documentais, notas de campo, relatórios parciais e finais produzidos pelas discentes apoiadoras e pelas coordenadoras, destacando o funcionamento do PAEQUI em dois grupos na unidade 3, campus de Marabá. Objetivou-se analisar os avanços e desafios na implementação dessa política de permanência voltada para os estudantes quilombolas na instituição. Constatou-se que o Programa possui experiências exitosas e desafios quanto a ações articuladas entre a Pró-Reitoria de Ensino de Graduação (PROEG) e as coordenações dos grupos de apoiadores que possibilitem efetivamente o sucesso acadêmico dos discentes apoiados.
\end{abstract}

Palavras-chave: Ações afirmativas. Estudantes quilombolas. Unifesspa. Programa de Ensino.

\section{THE QUILOMBOLA STUDENT SUPPORT PROGRAM (PAEQUI) AS A PERMANENCE POLICY IN A UNIVERSITY OF THE AMAZON (UNIFESSPA-PA)}

\begin{abstract}
The work analyses the experience of the Quilombola Student Support Program (PAEQUI), a policy concerned with the permanence of quilombola students entering Unifesspa through the Specific Indigenous and Quilombola Selection Process (PSIQ). The study was carried out with the analysis of documentary sources, field notes, partial and final reports produced by the supporting students and the coordinators, highlighting the functioning of PAEQUI in two groups in unit 3, in Marabá campus. The objective was to analyze the advances and challenges in the implementation of this permanence policy aimed at quilombola students at the institution. It was found that the Program has successful experiences and challenges regarding articulated actions between the Office of Undergraduate Studies (PROEG) and the coordinators of the groups of supporters that effectively enable the academic success of the supported students.
\end{abstract}

Keywords: Affirmative actions. Quilombola students. Unifesspa. Teaching Program.

\footnotetext{
${ }^{1}$ Professora Adjunta na Universidade Federal do Sul e Sudeste do Pará (Unifesspa). Doutora em Linguística (UFSC/SC). Exerce liderança compartilhada no Grupo de Estudos Interculturais das Amazônias (GEIA/CNPq/UNIFESSPA). Está em função administrativa na Coordenadoria de Apoio à Diversidade Étnico-Racial [CADER] do Núcleo de Ações Afirmativas, Diversidade e Equidade (NUADE/UNIFESSPA).

${ }^{2}$ Professora Adjunta na Universidade Federal do Sul e Sudeste do Pará (Unifesspa). Docente no Programa de Pós-Graduação em História e no ProfHistória. Doutora em História Social pela PUC-SP. Editora da Revista Escritas do Tempo. Presidente da Comissão Permanente para Diversidade, Heteroidentificação e Etnicidade da Unifesspa. Integra o Grupo de Mulheres Carolinas Leitoras (Marabá-PA).

${ }^{3}$ Mestranda do Programa de Pós-Graduação em Planejamento e Desenvolvimento Urbano e Regional na Amazônia. Bacharela em Saúde Coletiva pela Universidade Federal do Sul e Sudeste do Pará UNIFESSPA. Atuou como bolsista apoiadora no Programa de Apoio ao Estudante Quilombola - PAEQUI, sob orientação da Profa. Dra. Maria Cristina Macedo Alencar.
} 


\section{EL PROGRAMA DE APOYO AL ESTUDIANTE QUILOMBOLA (PAEQUI) COMO POLÍTICA DE ESTANCIA EN UNA UNIVERSIDAD DE LA AMAZONIA (UNIFESSPA-PA)}

Resumen: Este trabajo investiga la experiencia del Programa de Apoyo al Estudiante Quilombola (PAEQUI), una política preocupada con la permanencia de los estudiantes quilombolas que ingresan a Unifesspa a través del Proceso de Selección Específica Indígena y Quilombola (PSIQ). El estudio fue realizado con el análisis de fuentes documentales, notas de campo, informes parciales y finales producidos por los estudiantes de apoyo y por los coordinadores, destacando el funcionamiento del PAEQUI en dos grupos en la unidad 3, campus de Marabá. El objetivo fue analizar los avances y desafíos en la implementación de esta política de permanencia dirigida a los estudiantes quilombolas de la institución. Fue constatado que el Programa cuenta con experiencias exitosas y desafíos en relación a acciones articuladas entre la PROEG y los coordinadores de los grupos de apoyo que efectivamente posibilitan el éxito académico de los estudiantes apoyados.

Palabras clave: Acciones afirmativas. Estudiantes quilombolas. Unifesspa. Programa de enseñanza.

Fogo!...Queimaram Palmares, Nasceu Canudos.

Fogo!...Queimaram Canudos, Nasceu Caldeirões.

Fogo!...Queimaram Caldeirões, Nasceu Pau de Colher.

Fogo!...Queimaram Pau de Colher... E nasceram, e nascerão tantas outras comunidades que os vão cansar se continuarem queimando Porque mesmo que queimem a escrita,

Não queimarão a oralidade.

Mesmo que queimem os símbolos,

Não queimarão os significados.

Mesmo queimando o nosso povo,

Não queimarão a ancestralidade.

(NEGO BISPO, 2015, p. 46).

\section{Introdução}

O presente artigo discute aspectos da experiência de realização do Programa de Apoio ao Estudante Quilombola (PAEQUI), que constitui uma política preocupada com a permanência de estudantes quilombolas ingressantes na Universidade Federal do Sul e Sudeste do Pará (UNIFESSPA) via Processo Seletivo Específico Indígena e Quilombola (PSIQ). Tal programa, existente desde o ano de 2017 (antes em forma de editais de monitoria), procura apoiar pedagogicamente tais estudantes, minimizando os impactos da chegada à universidade, ambiente acadêmico e muito distinto das realidades comunitárias de onde esses grupos sociais são provenientes. 
DOI: 10.47694/issn.2674-7758.v3.i7.2021.124146

Neste texto evidenciamos elementos sobre o funcionamento do PAEQUI, atentando para a experiência de dois grupos coordenados na unidade 3 (Marabá) da UNIFESSPA $^{4}$. Integraram a equipe as coordenadoras Maria Cristina Macedo Alencar, da Faculdade de Educação do Campo, e Karla Leandro Rascke, da Faculdade de História, tendo como bolsistas apoiadoras as estudantes de graduação Jheyciele Naira dos Santos (Saúde Coletiva), Dhulia Braina Leite Lima (Ciências Econômicas), Silvia Cristina Farias da Silva (Agronomia), Rafaela Regina Santos Castro (Ciências Econômicas), Taiana Trindade Sena (Saúde Coletiva) e Taynara Oliveira Lopes (Agronomia).

Para fins deste artigo, utilizamos como documentação para análise os relatórios parciais e finais produzidos pelas discentes apoiadoras e coordenadoras, bem como as anotações de campo das discentes e também as anotações e os registros das reuniões de grupo e das reuniões entre coordenações e Pró-Reitoria de Ensino de Graduação (PROEG).

\section{Ações afirmativas para estudantes quilombolas na UNIFESSPA}

Segundo dados do informativo Desigualdades Sociais por Cor ou Raça no Brasil (2018) elaborado pelo Instituto Brasileiro de Geografia e Estatística (IBGE), em 2018 os estudantes de 18 a 24 anos, autodeclarados negros (pretos e pardos), representavam 55,6\% dos matriculados em universidades públicas no Brasil. Dados de uma pesquisa da Associação Nacional dos Dirigentes das Instituições Federais de Ensino Superior (Andifes), do mesmo período, davam conta de que esses estudantes representavam 51,2\% das matrículas nas Instituições Federais de Ensino Superior (IFES) brasileiras (RIBEIRO, 2019, p. 20).

Esses dados demonstram uma realidade inédita, pois pela primeira vez na história do país o número de pessoas negras no Ensino Superior foi mais próximo do percentual de pessoas negras na população brasileira. Tal realidade pode ser entendida como um dos impactos positivos das políticas de cotas para estudantes negros em nossas universidades. Lembremos que nos anos 1990 os estudantes negros (pretos e pardos) representavam somente 2\% dos matriculados no Ensino Superior (Cf. HENRIQUES, 2001).

\footnotetext{
${ }^{4}$ A Unifesspa é uma instituição multicampi, constituída de cinco campi, os quais estão localizados nas cidades de São Félix do Xingu, Santana do Araguaia, Xinguara, Marabá e Rondon do Pará, atendendo a demanda de formação no Ensino Superior em vários municípios da região Sul e Sudeste do Pará. No campus localizado na cidade de Marabá existem três unidades em bairros distintos.
} 
As cotas raciais têm se mostrado um "instrumento veloz de transformação da realidade de exclusão das pessoas negras do acesso ao ensino superior no Brasil" (MUNANGA, 2001, p. 34). Em nosso país o racismo estrutura o funcionamento da sociedade. Herança do sistema colonial sobre o qual se erigiu o país, a população negra tem sido tratada como mercadoria e tendo negados os direitos básicos e o acesso às riquezas por ela produzida, enquanto a população branca é historicamente beneficiada. Nossa sociedade se organiza e funciona a partir de uma "estrutura de poder que confere privilégio racial a determinado grupo, criando mecanismos que perpetuam desigualdades" (RIBEIRO, 2019, p. 14).

A exclusão do processo de aquisição escolar, principalmente, do acesso ao Ensino Superior, apresenta-se como um "núcleo de desvantagens que indivíduos negros ou pardos sofrem na sociedade brasileira" (HASENBALG; SILVA, 1999, p. 46), dificultando o seu acesso aos bens culturais e posições sociais mais elevadas na nossa sociedade, reflexo do racismo que nela opera.

Nessa dinâmica, o aparelho educacional tem se constituído, de forma quase absoluta, para os racialmente inferiorizados, como fonte de múltiplos processos de aniquilamento da capacidade cognitiva e da confiança intelectual. É fenômeno que ocorre pelo rebaixamento da autoestima que o racismo e a discriminação provocam no cotidiano escolar; pela negação aos negros da condição de sujeitos de conhecimento, por meio da desvalorização, negação ou ocultamento das contribuições do continente africano e da diáspora africana ao patrimônio cultural da humanidade; pela imposição do embranquecimento cultural e pela produção do fracasso e evasão escolar (RIBEIRO, 2019, p. 24).

A política de cotas no acesso ao Ensino Superior é um exemplo de Ação Afirmativa implementada pelo Estado brasileiro que se fundamenta nas regras de discriminação positiva prescritas na Constituição de 1988 (MUNANGA, 2001, p. 35). Conforme bem destacou Munanga (2001):

As chamadas políticas de ação afirmativa são muito recentes na história da ideologia anti-racista. Nos países onde já foram implantadas (Estados Unidos, Inglaterra, Canadá, Índia, Alemanha, Austrália, Nova Zelândia e Malásia, entre outros), elas visam oferecer aos grupos discriminados e excluídos um tratamento diferenciado para compensar as desvantagens devidas à sua situação de vítimas do racismo e de outras formas de discriminação (MUNANGA, 2001, p. 31).

Ao se analisar os dados do acesso ao Ensino Superior no Brasil observa-se uma disparidade histórica no ingresso de pessoas negras, indígenas, pobres e oriundas de escola pública a esse nível da educação formal. Essa disparidade é motivada pelas desigualdades sociais, econômicas e raciais. Assim, resultado de muitas mobilizações dos 
movimentos de homens e mulheres negras e negros e intelectuais antirracistas, o Estado brasileiro instituiu uma política de ação afirmativa com vistas a reparar a histórica exclusão desses segmentos da sociedade do acesso ao Ensino Superior.

Tal política articula-se a um movimento mais amplo em torno de políticas educacionais e de combate ao racismo. Como nos lembra Gomes (2018) ao destacar a importância do documento elaborado em preparação à participação do Brasil na "III Conferência Mundial de Combate ao Racismo, à Discriminação Racial, à Xenofobia e à Intolerância Correlatas", ocorrida em Durban, na África do Sul, de 31 de agosto a 7 de setembro de 2001, para a implementação das cotas étnico-raciais no acesso ao Ensino Superior.

E, antes disso, a grande contribuição da "Marcha Zumbi dos Palmares pela vida e contra todas as formas de discriminação", realizada em 20 de novembro de 1995, como um marco na construção de uma agenda de políticas e ações afirmativas para as pessoas negras no Brasil. As cotas étnico-raciais no Ensino Superior são, portanto, resultado de décadas de mobilização e lutas antirracistas, uma medida reparatória da dívida histórica do Estado brasileiro com a população negra e indígena do país.

Além disso, na primeira década do século XXI, tivemos a promulgação da Lei Federal 10.639/03, dispondo acerca da obrigatoriedade do ensino de história e cultura afro-brasileira e africana nos diferentes níveis de ensino e ainda na criação da Secretaria Nacional de Políticas de Promoção da Igualdade Racial (SEPPIR), nesse mesmo ano ${ }^{5}$. No intuito de estimular o processo de implementação da referida lei, em 2004, foram elaboradas e publicadas as Diretrizes Curriculares Nacionais para a Educação das Relações Étnico-Raciais e para o Ensino de História e Cultura Afro-brasileira e Africana para orientar as instituições de ensino em diferentes graus quanto às atividades destinadas à educação das relações étnico-raciais, bem como avaliá-las e supervisioná-las (SILVA, 2007, p. 490).

Cinco anos mais tarde, por proposição do Comitê Técnico de Diversidade para Assuntos Relacionados à Educação dos Afro-Brasileiros do Ministério da Educação (CADARA/MEC), em parceria com a Organização das Nações Unidas para a Educação, a Ciência e a Cultura (UNESCO), iniciou-se uma série de consultas a instituições da sociedade civil e do Estado, com o intuito de coletar sugestões sobre a melhor forma de

\footnotetext{
${ }^{5}$ A SEPPIR foi criada com o objetivo de enfrentar o racismo no Brasil. Idealizada no âmbito do Governo Federal em 2003, atualmente está vinculada ao Ministério da Justiça e Cidadania (MJC).
} 
acelerar a implantação da Lei Federal 10.639/03 (CARDOSO; RASCKE; LIMA; PACHECO; JESUS, 2014). Esses encontros, denominados Diálogos Regionais, culminaram num grande evento em Brasília, que delineou, em 2009, o Plano Nacional de Implementação das Diretrizes Curriculares Nacionais para a Educação das Relações Étnico-Raciais e para o Ensino de História e Cultura Afro-Brasileira e Africana (BRASIL, 2009).

Com a chamada "lei de cotas", a Lei n ${ }^{\circ} 12.711$, de 29 de agosto de 2012, instituiuse a reserva de $50 \%$ das vagas ofertadas em todas as Universidades Federais e nas Instituições Federais de Ensino Técnico de nível médio no país, por curso e por turno, às pessoas que tenham cursado todo o Ensino Médio em escola pública e, dentre essas, vagas com recorte social e econômico e também étnico-racial, conforme os artigos $1^{\circ}$ e $3^{\circ}$ :

Art. $1^{\circ}$ As instituições federais de educação superior vinculadas ao Ministério da Educação reservarão, em cada concurso seletivo para ingresso nos cursos de graduação, por curso e turno, no mínimo 50\% (cinquenta por cento) de suas vagas para estudantes que tenham cursado integralmente o ensino médio em escolas públicas.

Parágrafo único. No preenchimento das vagas de que trata o caput deste artigo, $50 \%$ (cinquenta por cento) deverão ser reservados aos estudantes oriundos de famílias com renda igual ou inferior a 1,5 salário-mínimo (um salário-mínimo e meio) per capita.

Art. $3^{\circ}$ Em cada instituição federal de ensino superior, as vagas de que trata o art. $1^{\circ}$ desta Lei serão preenchidas, por curso e turno, por autodeclarados pretos, pardos e indígenas e por pessoas com deficiência, nos termos da legislação, em proporção ao total de vagas no mínimo igual à proporção respectiva de pretos, pardos, indígenas e pessoas com deficiência na população da unidade da Federação onde está instalada a instituição, segundo o último censo da Fundação Instituto Brasileiro de Geografia e Estatística - IBGE (BRASIL, 2012).

A proposta inicial da lei, motivada pelas demandas, articulações e pressões exercidas pelos movimentos de homens e mulheres negras e negros e intelectuais antirracistas no Brasil, por uma política efetiva de reparação da exclusão dessas pessoas do acesso ao Ensino Superior, provocou amplo debate nacional e culminou na lei que ampliou seus benefícios a outro segmento da população que também é vítima do racismo em nossa sociedade, os povos indígenas. Tal debate regulamentou políticas institucionais já vigentes em inúmeras instituições de Ensino Superior, legitimando e tornando constitucional as chamadas cotas étnicas/raciais.

É inegável a relevância da "lei de cotas" para a democratização do acesso ao Ensino Superior, contudo a lei não assegurou a permanência e o êxito dos estudantes que 
ingressam beneficiados por essa lei. Diante disso tornou-se um imperativo para as Instituições de Ensino Superior (IES) desenvolver políticas internas específicas para garantir o acolhimento e a permanência dos estudantes cotistas.

Importante aqui também ressaltar que, dentre as propostas de políticas públicas elencadas no documento apresentado na Marcha para Zumbi (1995), a terceira proposta tratava de um programa de superação do racismo e da desigualdade racial que dava destaque para a educação e para a temática dos quilombos (SILVA; TRIGO; MARÇAL, 2015, p. 250-251). Atualmente a noção de "quilombo" se refere a:

[...] comunidades ou agrupamentos, cujas práticas cotidianas, na manutenção e reprodução de seus modos de vida característicos, contribuam para a consolidação de um território próprio, valorizando elementos como histórias de resistências, experiências coletivas e diferentes trajetórias históricas e políticas de determinada coletividade (LEITE, 2000 apud GOMES, 2018, p. 109).

Em 2018 as áreas registradas e certificadas pela Fundação Cultural Palmares $(\mathrm{FCP})^{6}$ como comunidades quilombolas somavam 3.018 territórios em todo o país (GOMES, 2018, p. 109). No estado do Pará são mais de 528 comunidades, localizadas em 65 municípios em 62 terras tituladas ${ }^{7}$. O ingresso de estudantes oriundos dessas comunidades nas IES do estado do Pará tem representado uma importante contribuição ao processo de produção do conhecimento científico a partir do diálogo com conhecimentos não eurocêntricos e, lentamente, a superação do epistemicídio característico do funcionamento de nossas instituições universitárias onde ainda quase não há espaço para a memória e a visão daqueles que têm resistido ao processo assimilatório imposto pelo Estado brasileiro, tais como os povos indígenas e as comunidades quilombolas (CARVALHO, 2010).

$\mathrm{O}$ ingresso de estudantes indígenas e negros, dentre esses os autodeclarados quilombolas, na UNIFESSPA se realiza não apenas por meio do cumprimento das medidas exigidas na Lei 12.711/2012, mas de critérios específicos definidos em editais de processo seletivo. Anualmente a instituição realiza o PSIQ em todos os cursos que oferece. Desde a sua criação, no ano de 2013, a UNIFESSPA oferta duas vagas por acréscimo para indígenas em todos os seus cursos. A partir do ano de 2014 a instituição

\footnotetext{
${ }^{6}$ Entidade vinculada ao Ministério da Cidadania, fundada no dia 22 de agosto de 1988 pelo Governo Federal. Trata-se de "instituição pública voltada para promoção e preservação dos valores culturais, históricos, sociais e econômicos decorrentes da influência negra na formação da sociedade brasileira". Dentre as suas atribuições está a de certificação das Comunidades Remanescentes de Quilombos (CRQs) (Cf. http://www.palmares.gov.br).

${ }^{7}$ Disponível em: http://cpisp.org.br/direitosquilombolas/observatorio-terras-quilombolas.
} 
passou a ofertar também, em todos os cursos, duas vagas por acréscimo para candidatos quilombolas e duas vagas para candidatos com deficiência, conforme determinado na Resolução n. ${ }^{\circ}$ 22/2014-Consepe/Unifesspa.

O PSIQ tem sido realizado em três etapas: a primeira exige o envio de documentação do candidato comprovando ter cursado todo o Ensino Médio em Escola Pública e seu pertencimento étnico com a comunidade ou povo; a segunda etapa envolve a realização de uma prova discursiva; e a terceira, uma entrevista presencial e individual com uma banca formada por professores e técnicos universitários da instituição com experiência em estudos e pesquisas ou ações desenvolvidas junto às comunidades indígenas e/ou quilombolas. Anualmente, porém, a minuta do edital que regulamenta o processo seletivo é revista e discutida em audiência pública com a comunidade acadêmica e representantes das comunidades indígenas e quilombolas, sendo reformulado a partir das considerações feitas nessas audiências.

Em 2021, tendo em vista a criação da Portaria n. 1177/2020-UNIFESSPA, que instituiu a Comissão Permanente para Diversidade, Heteroidentificação e Etnicidade e regulamenta o procedimento de ingresso para candidatos autodeclarados negros (pretos e pardos), indígenas, quilombolas e povos do campo para fins de preenchimento das vagas reservadas nos cursos e processos seletivos da UNIFESSPA, o PSIQ terá atuação dessa Comissão.

Como o foco de nossa reflexão aqui incide sobre a permanência dos estudantes quilombolas na UNIFESSPA, a seguir apresentamos e refletimos sobre alguns dados específicos desse segmento da comunidade acadêmica. No ano de 2014 ingressaram apenas dois estudantes quilombolas nos cursos de graduação da UNIFESSPA via PSIQ. Em 2016 ingressaram 30 estudantes (SANTOS; LUIZ, 2016, p. 5); em 2018, $50^{8}$ e em 2020, $49^{9}$ estudantes. Além do ingresso se tornou uma realidade para a instituição a necessidade de construção de políticas institucionais que garantam a permanência dos estudantes indígenas e quilombolas.

A UNIFESSPA tem conduzido o processo de construção das políticas de permanência de estudantes indígenas e quilombolas a partir de amplo debate com esses coletivos e suas organizações, bem como com lideranças das suas comunidades de origem. No ano de 2017, após várias reuniões, os estudantes quilombolas e pesquisadores que se

\footnotetext{
${ }^{8} \mathrm{Cf}$. https://www.unifesspa.edu.br/images/editais/editais_2018/Edital_resultado_final_psiq2018.pdf

${ }^{9}$ Cf. https://crca.unifesspa.edu.br/images/editais_2020/PSIQ-Edital_n_9-

Resultado_final_PSIQ_2020_Retificado.pdf
} 
dedicavam ao tema da educação escolar quilombola, educação escolar indígena e educação das relações étnico-raciais contribuíram com a Diretoria de Planejamento e Projetos Educacionais (DPROJ-PROEG), na elaboração de dois editais com bolsas para estudantes atuarem como apoiadores dos estudantes quilombolas e indígenas ingressantes, orientando-os nas atividades acadêmicas.

A primeira experiência de apoio à permanência dos estudantes indígenas e quilombolas na UNIFESSPA foi realizada com o Programa de Monitoria Indígena e Quilombola, criado no ano de 2017. Atuavam como bolsistas desse programa de monitoria estudantes selecionados, prioritariamente, entre candidatos indígenas e quilombolas. O objetivo da monitoria ofertada aos estudantes indígenas e quilombolas era o acompanhamento do desempenho acadêmico desses estudantes, uma vez que se verificou entre eles a ocorrência de um alto índice de evasão e reprovação (UNIFESSPA, 2017).

O foco da reflexão que aqui apresentamos é o PAEQUI, o qual, junto com o Programa de Apoio ao Estudante Indígena (PAIND), sucedeu, no ano de 2018, o Programa de Monitoria Indígena e Quilombola, cujos resultados de avaliação dos professores coordenadores, dos bolsistas e da Associação dos Discentes Indígenas e Quilombolas (ADIQUI) ${ }^{10}$ foram incorporados pela DPROJ-PROEG para o novo Programa. O foco das ações do PAIND e do PAEQUI é apoiar os estudantes indígenas e quilombolas ingressantes na vida acadêmica e contribuir para sua permanência e sucesso acadêmico.

Para Gomes (2018) o "Seminário de Políticas Afirmativas e Diversidade", realizado na UNIFESSPA nos dias 14 a 16 de novembro de 2016, foi catalisador para o encaminhamento dessa política que objetivou a permanência dos estudantes que ingressam na instituição pelo PSIQ. Nesse evento, dentre as várias atividades realizadas, houve a discussão em Grupos de Trabalho (GT's) com participação de técnicos da instituição, estudantes e lideranças de diversos segmentos de grupos minoritários que são discentes na UNIFESSPA. Dentre os GT's, o GT 2 - Ações Afirmativas para Quilombolas, do qual participaram servidores da UNIFESSPA, estudantes quilombolas das comunidades do Umarizal e Nova Jutaí e a presidente de uma associação da

\footnotetext{
${ }^{10}$ A ADIQUI foi desmembrada em 2019, tornando-se Associação dos Discentes Indígenas da Unifesspa (ADIU) e Centro Acadêmico dos Estudantes Quilombolas Zumbi/Dandara dos Palmares.
} 
DOI: 10.47694/issn.2674-7758.v3.i7.2021.124146

comunidade Nova Jutaí (GOMES, 2018, p. 118), foram elaboradas várias propostas de políticas de permanência para esse grupo.

Quadro 1: Propostas do GT 02 - Seminário de Políticas Afirmativas e Diversidade da UNIFESSPA (2016)

\begin{tabular}{|c|c|}
\hline Área & Propostas \\
\hline \multirow{2}{*}{ Ensino } & $\begin{array}{l}\text { Orientação sobre os procedimentos técnicos e acadêmicos de } \\
\text { vinculação (habilitação, matrícula, início das aulas etc.) dos } \\
\text { ingressantes à Unifesspa nas cerimônias de } \\
\text { recepção/acolhimento dos calouros, de forma mais consistente. }\end{array}$ \\
\hline & $\begin{array}{l}\text { Orientação sobre os sistemas de informática e comunicação da } \\
\text { Unifesspa (SIGs, e-mail, sites, telefones, WhatsApp etc.) em } \\
\text { eventos de recepção dos calouros. }\end{array}$ \\
\hline \multirow{10}{*}{ Extensão } & $\begin{array}{l}\text { Problematizar os propósitos das ações de permanência dos } \\
\text { discentes (avaliação, cumprimento dos resultados etc.). }\end{array}$ \\
\hline & $\begin{array}{l}\text { Maior participação das representações quilombolas nas } \\
\text { atividades desenvolvidas pela/na Universidade. }\end{array}$ \\
\hline & $\begin{array}{l}\text { Apoiar os discentes quilombolas na promoção de seus direitos } \\
\text { na comunidade e na Universidade e na realização de ações em } \\
\text { suas comunidades. }\end{array}$ \\
\hline & $\begin{array}{l}\text { Reforço a oferta de cursos de informática para os discentes } \\
\text { quilombolas, voltados a produção acadêmica. }\end{array}$ \\
\hline & $\begin{array}{l}\text { Estratégias de comunicação e divulgação de atividades } \\
\text { desenvolvidas no espaço da universidade. }\end{array}$ \\
\hline & Palestras, minicursos, oficinas sobre produção de texto e leitura. \\
\hline & Restaurante Universitário - RU \\
\hline & $\begin{array}{l}\text { Apoiar o debate sobre estratégias de solidariedade entre os } \\
\text { quilombolas para permanência na Universidade }\end{array}$ \\
\hline & $\begin{array}{l}\text { Promover oficinas, debates, minicursos sobre a relação e troca } \\
\text { de experiências entre ensino, pesquisa e extensão. }\end{array}$ \\
\hline & $\begin{array}{l}\text { Aporte para o desenvolvimento das atividades de pesquisa e } \\
\text { extensão nas comunidades quilombolas (concessão de bolsas, } \\
\text { transportes, materiais etc.). }\end{array}$ \\
\hline Pesquisa & $\begin{array}{l}\text { Apoiar a pesquisa pelos discentes e voltadas às comunidades } \\
\text { quilombolas. }\end{array}$ \\
\hline
\end{tabular}

Fonte: FERNANDES; GUIDO; SOARES (2016, p. 23-24).

Nos parágrafos a seguir refletimos como as ações realizadas no PAEQUI (2018 2019) atenderam as demandas do ensino e parte das demandas apresentadas como atividade de extensão propostas por estudantes e lideranças quilombolas no Seminário de Ações Afirmativas da UNIFESSPA, conforme apresentado no Quadro 1. 
DOI: 10.47694/issn.2674-7758.v3.i7.2021.124146

\section{A experiência do PAEQUI 2018-2019}

O PAEQUI funcionou nos anos de 2018-2019, regido pelo Edital 10/2018PROEG, a partir da atuação de coordenadores e bolsistas - discentes apoiadores - nos campi de Rondon do Pará e Marabá, neste último nas suas três unidades. De acordo com o Edital, a distribuição das vagas para apoiadores com bolsa remunerada e voluntários ocorreu a partir da divisão em Grupos (1,2, 3 e 4), sendo que cada um tinha como objetivo realizar a cobertura dos discentes que correspondiam a tais grupos.

O grupo 1 era responsável por atender 25 estudantes quilombolas dos cursos de Direito, Geografia, Pedagogia, Ciências Sociais e História; o grupo 2 ficou responsável por 27 estudantes dos cursos de Engenharia de Minas, Engenharia Mecânica, Engenharia de Materiais, Engenharia da Computação, Engenharia Civil, Engenharia Química, Ciências Naturais, Geologia, Química, Matemática e Sistema de Informação; o grupo 3 ficou responsável por 26 estudantes dos seguintes cursos: Ciências Biológicas, Saúde Coletiva, Psicologia, Agronomia, Ciências Econômicas, Letras Português, Letras Inglês e Artes Visuais; e o grupo 4 que era responsável por atender 4 estudantes quilombolas do curso de Administração, localizado no campi de Rondon do Pará.

Tratamos aqui especificamente da experiência do Grupo 3 que, para atender os 26 estudantes que compunham o grupo, contou com duas coordenadoras e seis alunas de graduação na condição de bolsistas apoiadoras remuneradas. Desse total de estudantes 13 demandaram o acompanhamento pelas bolsistas apoiadoras. Eram estudantes dos seguintes cursos: Agronomia (2), Psicologia (3), Saúde Coletiva (4), Ciências Econômicas (1), Ciências Biológicas (2), Letras Português (1).

Dentre as bolsistas apoiadoras duas eram quilombolas e todas as seis do Grupo 3 desenvolviam o acompanhamento dos estudantes quilombolas. Além disso, também realizavam pesquisas e estudos no campo das relações étnico-raciais e desenvolviam diversas estratégias para identificar e solucionar os problemas enfrentados por esses estudantes.

Os estudantes apoiados pelo Programa são provenientes das comunidades quilombolas Nova Jutaí, Igarapé Preto e Umarizal, situadas na zona rural de Breu Branco e Baião, no estado do Pará. A maioria desses estudantes ingressou na UNIFESSPA através do PSIQ, homens e mulheres advindos de suas comunidades rurais; jovens e adultos que trazem em sua bagagem uma educação escolar precarizada, e foram para a 
cidade de Marabá morar em pequenas casas (Kitnets) nas proximidades da Unidade I, longe de suas famílias e territórios conhecidos.

Uma parte significativa dos estudantes quilombolas recebiam o auxílio financeiro oriundo do Programa Bolsa Permanência do Ministério da Educação (MEC), que disponibiliza bolsas específicas para discentes indígenas e quilombolas. Compete mencionar que esses estudantes quilombolas estavam em diferentes cursos de graduação, possuíam experiências distintas "sexualidade, identidade de gênero, idade, identidade etnicorracial" (SANTOS, 2017, p. 13). Portanto, é possível:

[...] identificar que a maioria dos discentes quilombolas passaram por várias dificuldades em suas trajetórias educacionais para acessarem e mesmo para concluírem o ensino médio, seja porque alguns são forçados a migrarem para outros municípios e/ou comunidades que possuem o ensino médio, pois em alguns casos, há comunidades que não possuíam nem mesmo o ensino fundamental, ou quando tinha o ensino médio, era ofertado no sistema modular de ensino e de forma muito fragilizada. (UNIFESSPA, 2017, p. 70).

Para acessar o Ensino Superior são necessários esforços ainda maiores, em cidades distantes e desconhecidas, em um lugar novo e cheio de desafios para esses estudantes que, em sua maioria, provém de áreas rurais. Assim, precisam construir redes de apoio para sobreviver, como relata a discente apoiadora Taiana Sena no relatório parcial (2019): "os estudantes quilombolas possuem grupos de futebol” (SENA, 2019, p. 3). A vivência em coletividade constitui experiências significativas para a aprendizagem, sem, no entanto, cair no erro de desvalorizar os saberes tradicionais de seus povos. Conforme Gomes, "tal situação coloca os sujeitos quilombolas e suas subjetividades como elementos importantes na criação de saberes, que potencializam ações específicas na luta contra o racismo na sociedade e nas universidades brasileiras" (GOMES, 2018, p. 3).

Conforme se observa na Figura 1, a seguir, as funções realizadas pelas apoiadoras do PAEQUI visavam o sucesso acadêmico dos(as) estudantes quilombolas. Mesmo com entraves à realização dessas funções, tais como falta de infraestrutura, capacitação e subsídios, as discentes apoiadoras esforçavam-se por realizar suas atividades, especialmente por meio da busca ativa dos(das) estudantes. Além disso, conforme relatório de Rafaela Castro (2018-2019), o empenho para divulgação das ações do Programa e a concretização dos atendimentos eram constantes: "para garantir que os atendimentos fossem de conhecimento dos alunos foram produzidos cartazes e estes foram colocados em todos os murais do campus III, além disto eu fui atrás dos discentes 
quilombolas, tanto pessoalmente quanto via mensagem no whatsapp" (CASTRO, 2019, p. 2).

Figura 1: Cartaz de divulgação das ações do PAEQUI 2018-2019.

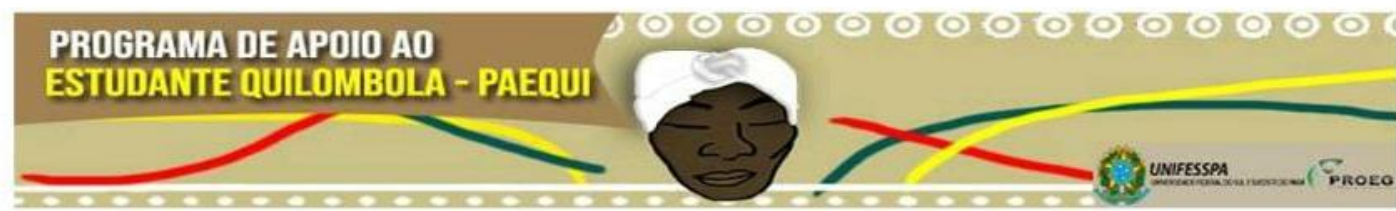

\section{O QUE É O PAEQUI?}

O Programa de Apoio ao Estudante Quilombola foi criado com o objetivo de fomentar a inclusão dos discentes quilombolas nas atividades de ensino, pesquisa e extensão, contribuindo, dessa forma, para a sua permanência e êxito acadêmico. O PAEQUI justifica-se em razão das especificidades dos discentes quilombolas com relação à organização social de suas comunidades, condição geográfica, costumes, línguas, crenças e tradições, amparadas pela Constituição Federal (1988).

\section{A! INFORMAÇÕES IMPORTANTES}

\begin{tabular}{|c|c|c|c|c|}
\hline APOIADORA & CONTATO & CURSOS ATENDIDOS & HORÁRIO & COORDENADORA \\
\hline $\begin{array}{l}\text { Jheyciele Naira } \\
\text { dos Santos }\end{array}$ & $\begin{array}{l}\text { Jheyciellenaira@gmail.com } \\
\text { (94) 99277-1283 }\end{array}$ & $\begin{array}{c}\text { Ciências Biológicas } \\
\text { Psicologia } \\
\text { Saúde Coletiva }\end{array}$ & $\begin{array}{l}\text { Terça-feira } \\
\text { 14:00 às } 18: 00 \\
\text { Sexta-feira } \\
14: 00 \text { às } 18: 00\end{array}$ & \multirow{3}{*}{$\begin{array}{l}\text { Maria Cristina } \\
\text { Macedo Alencar }\end{array}$} \\
\hline $\begin{array}{l}\text { Dhulia Braina } \\
\text { Leite Lima }\end{array}$ & $\begin{array}{l}\text { brainalima@gmail.com } \\
\text { (94)98152-1054 }\end{array}$ & $\begin{array}{l}\text { Ciências Econômicas } \\
\text { Artes Visuais }\end{array}$ & $\begin{array}{l}\text { Quarta-feira } \\
\text { 08:00 às 12:00 } \\
\text { Quinta-feira } \\
14: 00 \text { às } 18: 00\end{array}$ & \\
\hline $\begin{array}{l}\text { Silvia Cristina } \\
\text { Farias da Silva }\end{array}$ & $\begin{array}{l}\text { silviacrissf97@gmail.com } \\
\text { (94) } 992976784\end{array}$ & $\begin{array}{c}\text { Agronomia } \\
\text { Letras inglês } \\
\text { Letras português }\end{array}$ & $\begin{array}{l}\text { Segunda-feira } \\
\text { 08:00 às } 12: 00 \\
\text { Terça-feira } \\
14: 00 \text { às } 18: 00\end{array}$ & \\
\hline $\begin{array}{l}\text { Rafaela Regina } \\
\text { Santos Castro }\end{array}$ & $\begin{array}{c}\text { rafaelareginasantoscastro@g } \\
\text { mail.com } \\
\text { (94) } 992529513\end{array}$ & $\begin{array}{l}\text { Ciências Economicas } \\
\text { Artes Visuais }\end{array}$ & $\begin{array}{l}\text { Segunda-feira } \\
08: 00 \text { às } 12: 00 \\
\text { Quinta-feira } \\
08: 00 \text { às } 12: 00\end{array}$ & \multirow{3}{*}{$\begin{array}{l}\text { Karla Leandro } \\
\text { Rascke }\end{array}$} \\
\hline $\begin{array}{c}\text { Taiana } \\
\text { Trindade Sena }\end{array}$ & $\begin{array}{l}\text { senataiana@live.com } \\
\text { (91)98160-5243 }\end{array}$ & $\begin{array}{l}\text { Ciências Biológicas } \\
\text { Psicologia } \\
\text { Saúde Coletiva }\end{array}$ & $\begin{array}{l}\text { Quarta-feira } \\
14: 00 \text { às } 18: 00 \\
\text { Quinta - feira } \\
14: 00 \text { às } 18: 00\end{array}$ & \\
\hline $\begin{array}{c}\text { Taynara } \\
\text { Oliveira Lopes }\end{array}$ & $\begin{array}{l}\text { taynara@unifesspa.edu.br } \\
\text { (94)99122-6221 }\end{array}$ & $\begin{array}{c}\text { Agronomia } \\
\text { Letras inglês } \\
\text { Letras portugues }\end{array}$ & $\begin{array}{l}\text { Quinta-feira } \\
08: 00 \text { às 12:00 } \\
\text { Sexta-feira } \\
08: 00 \text { às } 12: 00\end{array}$ & \\
\hline
\end{tabular}

Os atendimentos ocorrem na sala 3 da FAHIST (unidade 3), no espaço do Grupo de Pesquisa GREAL.

\section{FUNÇÕES DAS APOIADORAS (Unidade 3)}

$\checkmark$ Auxiliar as professoras nas tarefas didáticas e elaboração de trabalhos;

$\checkmark$ Auxiliar os alunos, individualmente ou em grupos, em sala de aula e em horários definidos:

$\checkmark$ Facilitar o relacionamento entre alunos/as e professor/a na execução e melhoria do Plano de atividades;

$\checkmark$ Avaliar o andamento da atividade de ensino do ponto de vista do aluno, apresentando sugestōes ao professor orientador:

$\checkmark$ Realizar estudos teóricos sob a orientação da coordenadora; entre outros. 
Através do programa concretizou-se experiências compartilhadas entre os discentes quilombolas apoiados, as discentes apoiadoras e as professoras coordenadoras com o objetivo de garantir a permanência e a formação desses estudantes. Nisto foi possível verificar a contribuição de forma significativa no processo de ensinoaprendizagem dos atores envolvidos. Destaca-se que esse processo refletiu diretamente na emancipação do conhecimento, na construção de redes de saberes e ampliação da participação das bolsistas e discentes atendidos na vida acadêmica.

É necessário, porém, nas próximas edições do PAEQUI elaborar instrumentos para um estudo mais aprofundado de modo a gerar informações que possibilitem sabermos as problemáticas que têm resultado na pouca participação dos(as) estudantes quilombolas nas atividades que foram ofertadas pelo programa. Uma hipótese pode ser o preconceito em relação a esses grupos na universidade e os receios ou estigmas dos estudantes em utilizar o apoio ofertado por um Programa direcionado a um grupo específico. Outra hipótese pode estar vinculada às diferenças culturais e particularidades entre os grupos atendidos e as equipes do próprio Programa. Mesmo que o PAEQUI tenha contado com a participação de bolsistas apoiadores que são quilombolas, a cultura acadêmica e universitária pode gerar um desconforto e conflitos, muitas vezes afastando esses estudantes da própria vivência dinâmica da universidade ${ }^{11}$.

No entanto, como já mencionado, as possíveis hipóteses consequentemente levaram a baixa demanda de acompanhamentos regulares. Corroborando com a discente apoiadora Rafaela Castro (2018- 2019),

[...] talvez eles se sintam reprimidos, com vergonha ou queiram mostrar que não precisam de monitoria só pelo fato de serem quilombolas, há várias coisas que podem ser apontadas como causa da não participação, os discentes podem achar que não vamos ajudar tanto pelo fato de os apoiadores serem de outro curso.

Ao nos referimos ao PAEQUI é perceptível que na escrita e na fala trazemos o orgulho de termos um programa que tem ações de cunho político, social e acadêmico voltados às comunidades que historicamente foram postas às margens de qualquer decisão política, econômica e social. São notáveis as contribuições do Programa tanto para os discentes apoiados quanto para as apoiadoras, apesar das dificuldades logísticas e também,

\footnotetext{
${ }^{11}$ Até o presente momento não criamos um instrumento de avaliação que pudesse trazer informações sobre as percepções dos estudantes atendidos de forma mais sistematizada. Nos relatórios das bolsistas apoiadoras constam informações de falas e dos atendimentos desses estudantes, mas sem um instrumento de avaliação definido.
} 
às vezes, pedagógica, como evidenciamos no item subsequente. Assim sendo, percebemos que a Unifesspa vem construindo possibilidades para uma sociedade mais equânime.

Em termos positivos e de participação científica de discentes e docentes, o PAEQUI foi tema de apresentação de comunicação oral no evento II COPENE Norte Congresso Brasileiro de Pesquisadores Negros da Região Norte, ocorrido entre os dias 21 e 23 de agosto de 2019, na UFT, em Palmas, com a Comunicação Oral intitulada "Universidade para a diversidade: projeto de apoio aos discentes quilombolas da Unifesspa", feita pela bolsista apoiadora Silvia Cristina Farias, discente quilombola apoiadora.

\section{Dificuldades, Desafios e Avanços no Programa}

Durante o período de agosto de 2018 a dezembro de 2019, a equipe de coordenadores (professores e técnicos educacionais) que atuou no PAEQUI esteve em reuniões mensais com a PROEG, no sentido de pensar as ações então desenvolvidas, os impactos na permanência dos estudantes atendidos e também na ampliação do Programa. Tal modalidade de ação afirmativa era uma tentativa de reversão de um histórico de marginalização social vivenciada não apenas pelas comunidades quilombolas, mas pelos estudantes que se deslocam de suas comunidades, praticamente todas situadas em áreas rurais no estado do Pará, para alcançarem uma vaga no Ensino Superior público e gratuito.

A referida Pró-reitoria possuía até então 10 programas em andamento (março de 2019), sendo um deles o PAEQUI e outro o PAIND, direcionados especificamente a grupos atendidos pela Unifesspa por meio de Processos Seletivos Específicos. Nesse sentido, ao longo do percurso de desenvolvimento das ações, cada coordenação e também os bolsistas colocaram em questão a importância de uma política para a Universidade, no sentido não apenas de efetivar as ações já existentes, mas ampliá-las. A constituição de tal política viabilizaria um espaço físico destinado aos encontros da equipe do PAEQUI, bem como dos atendimentos específicos, individuais ou coletivos, realizados entre bolsista(s) apoiador(es) e estudante(s) apoiado(s) (RASCKE, 2019, s/p).

$\mathrm{Na}$ agenda das equipes do PAEQUI era permanente a preocupação com o alcance das ações, de modo que entre os debates estava a importância de uma aproximação com os Núcleos Docentes Estruturantes (NDEs) das faculdades, o que permitiria melhor articulação junto aos professores de cada curso e também o desenvolvimento de 
abordagens capazes de ampliar a importância do Programa e o atendimento aos discentes quilombolas, otimizando suas experiências na universidade e contribuindo para o êxito acadêmico.

Em termos de dificuldades encontradas quanto à efetivação e ampliação do Programa, durante os 18 meses de seu desenvolvimento, algumas instabilidades trouxeram à tona certas fragilidades, dada a ausência de uma política consolidada e constante do Plano de Desenvolvimento Institucional (PDI). Nesse sentido, a questão orçamentária, em especial com os cortes provenientes de repasses do governo federal, evidenciaram problemas quanto à manutenção de todas as bolsas dos bolsistas apoiadores.

Nesse contexto, ao mesmo tempo em que atores sociais (negros, indígenas, quilombolas e antirracistas) buscavam estratégias de garantir o direito à educação para grupos sociais historicamente marginalizados, houve cortes nos recursos da educação.

Os cortes no Programa Nacional de Assistência Estudantil (PNAES), cujos recursos mantêm muitas ações da Unifesspa e têm sofrido consecutivamente com grande diminuição orçamentária, dificultando ou inviabilizando ações, programas e projetos que enfoquem a permanência estudantil. Mas, após avaliações e diálogos realizados em conjunto por estudantes atendidos pelo PAEQUI, discentes apoiadores, professores coordenadores e PROEG, o Programa foi mantido, de modo a contemplar suas características específicas. Havia, naquele momento, a discussão de substituição do Programa por outro, destinado exclusivamente para estudantes ingressantes, mas sem qualquer especificidade direcionada a quilombolas ou indígenas, o que afetaria o próprio objetivo do PAEQUI e suas especificidades.

Ao mesmo tempo, em se tratando de editais específicos, qualquer alteração ou ajuste no Programa demandava a existência de novo edital, implicando uma demanda não apenas de pessoal para realização de todo esse processo, mas também de um período de tempo, o que inviabilizava, na prática, até mesmo a substituição de um bolsista. A partir desses debates e perspectiva, os editais periódicos para o Programa seriam um quesito, mas não o único instrumento que permitiria a existência da política.

No que tange ao comprometimento da PROEG, a partir das reuniões com coordenações, bolsistas apoiadores e estudantes apoiados, solicitou-se a inclusão dessa demanda no próximo PDI (2020-2024). A minuta deste, que se encontra em processo de tramitação no âmbito da esfera administrativa e para votação no Conselho Universitário (CONSUN), reforça que "a Unifesspa implementa diversas ações que visam não só 
aumentar o número de ingressantes em seus cursos, mas, acima de tudo, comprometer-se com a permanência dos seus alunos" (PDI, 2020, p. 69).

Para tanto a PROEG mantém em seu portfólio de programas de ensino, para o período 2020-2024, o PAEQUI e o PAIND, além do Programa de Apoio ao Discente Ingressante (PADI). Além disso, o citado documento menciona a implantação de um Comitê de Inclusão Social, "constituído por profissionais diversos, bem como por representantes da sociedade civil, dos povos indígenas, quilombolas e da pessoa com deficiência, com o objetivo de planejar e desenvolver ações voltadas para esses grupos" (UNIFESSPA, 2020, p. 78).

De acordo com o mesmo texto, o objetivo dessa pauta desmembra-se em outros específicos como "investigar a realidade, identificar demandas, orientar as práticas, apoiar os docentes e demais profissionais da Universidade e propor ações para a adequada inclusão de estudantes desde seu ingresso no curso, tanto na graduação como na pósgraduação" (idem).

Outro ponto importante observado nos encontros de socialização das experiências e andamento das ações, tratava-se da articulação entre os diferentes coordenadores e também entre as unidades de Marabá (I, II e III). Ações articuladas, envolvendo mais de uma coordenação e bolsista constituía possibilidade de criação de propostas de cursos, palestras, encontros, grupos de estudos e demais atividades compartilhadas. Assim, uma das intenções desse tipo de atividades, em conjunto, no coletivo, também era mobilizar a unidade, ou mesmo mais de uma unidade da UNIFESSPA, disponibilizando abordagens interdisciplinares para lidar com questões comuns, quais fossem: a permanência estudantil e o êxito desses acadêmicos.

Normalmente os alunos acabavam procurando mais as apoiadoras em momentos de entrega de trabalhos, apresentação de seminários em sala, datas de provas e afins. Isso implicava em um trabalho mais pontual, o que consideramos um problema do ponto de vista pedagógico, pois a sequência de trabalho e desenvolvimento do apoiado ficavam comprometidos. Assim, uma aproximação com os NDEs ${ }^{12}$ possibilitaria que a atuação em conjunto tivesse resultados mais efetivos na trajetória acadêmica de cada discente apoiado.

${ }^{12} \mathrm{O}$ NDE é um colegiado constituído de um grupo de docentes com atribuições acadêmicas de acompanhamento didático-pedagógico dos discentes. 
O PAEQUI contou com alguns desafios que envolviam o repensar de ações para o futuro. Consideramos que a realização de reuniões mensais, encontros de grupos de estudos quinzenais e contatos periódicos entre coordenações e bolsistas para debate de textos, acompanhamento das atividades desenvolvidas e também reflexões sobre ações afirmativas constituem questões importantes e capazes de articular diferentes áreas do conhecimento, visto sermos uma equipe multidisciplinar, tentando atuar interdisciplinarmente.

Ressaltamos que, no âmbito das dificuldades, alguns aspectos merecem notificação, como a ausência de uma sala, enquanto espaço físico e ponto de referência para atendimento do Programa, bem como para os atendimentos individuais aos estudantes, encontros de estudos, reuniões e afins. Um espaço que fosse referência para o PAEQUI e que permitisse a qualquer estudante interessado chegar à sala e se informar com detalhes sobre os auxílios oferecidos, constituiria uma fonte de acolhimento e também referência.

Importa também destacar que o Programa não alcançou, do ponto de vista institucional, uma produção em forma de relatório e avaliação de suas ações. Em virtude de equipe técnica e docente muito reduzida, a PROEG não publicou ainda um documento com dados estatísticos de avaliação, orientação e caminhos para a elaboração de uma política mais efetiva de permanência. Os dados e os relatórios existentes até o presente momento foram elaborados por bolsistas apoiadores(as) e também coordenadores(as) das ações.

Compete mencionar que o Edital 2020 do PAEQUI, lançado em fevereiro do mesmo ano e cujas propostas foram submetidas em março pelos interessados em coordenar ações, infelizmente foi suspenso em virtude da pandemia e da impossibilidade de atendimentos ou ações presenciais nesse contexto. Assim, há mais de um ano o Programa não tem ações programadas e/ou apoiadas. Tendo em vista os impactos do covid-19 na vida das pessoas e na educação formal, as aulas e demais atividades pedagógicas e acadêmicas estão suspensas em formato físico/presencial desde então, sendo a oferta de disciplinas realizadas de forma remota. Em se tratando de realidades díspares em relação ao acesso a equipamentos e também tecnologias capazes de uma conexão viável e estável, muitos estudantes tiveram que trancar disciplinas e/ou o curso, visando realizar o andamento deste apenas quando de seu retorno na modalidade presencial. 
A situação de pandemia trouxe à tona questões que envolvem o apoio a discentes quilombolas e suas dificuldades tecnológicas, pedagógicas e de estrutura adequada inclusive para viabilidade de aulas remotas, formato que tem sido utilizado enquanto alternativa de ensino nesse contexto atípico e delicado experimentado por toda a população mundial, com especificidades e dificuldades que se ampliam a depender dos contextos regionais, sociais, econômicos e políticos dos povos e dos Estados.

Outro aspecto que merece observação, já destacado em reunião entre coordenação, apoiadores e PROEG, é a necessidade de termos uma coordenação pedagógica que possa pensar estratégias e metodologias capazes de ampliar a eficácia do programa e o rendimento acadêmico dos alunos; bem como articular ações de pesquisa, ensino e extensão e o funcionamento de grupos de estudos, com participação de discentes apoiadores e apoiados, num movimento de incentivo desses discentes a participarem de eventos e também seguirem a carreira acadêmica (RASCKE, 2019, s/p).

Em termos gerais, diferentes ações, desenvolvidas de forma interdisciplinar, como as oficinas pedagógicas oferecidas e o acolhimento aos calouros também foram significativas no sentido de integração e experimentação do espaço e das ferramentas do universo acadêmico. Uma das questões apontadas pelos discentes apoiados foi a dificuldade de compreensão do ritmo universitário, da gestão do tempo e das demandas cotidianas da graduação. Nesse sentido, as ações desenvolvidas também permitiram contribuir no entendimento desse ambiente novo, acadêmico, com demandas muitas vezes alheias ao universo cultural de origem de nossos estudantes.

Por último, mas não menos importante, ressaltamos que o PAEQUI prioriza que os(as) bolsistas apoiadores sejam discentes quilombolas. Além de fortalecer a autoestima desses(as) discentes, isso contribui para que possam dimensionar mais elementos da vida universitária e vislumbrar outros horizontes e perspectivas de ascensão profissional e social. Consideramos que isso motiva esses(as) estudantes a lutarem com maior instrumental teórico e prático em defesa de suas comunidades e agendas políticas, para além do âmbito acadêmico.

Um aspecto positivo ainda não ressaltado envolve a possibilidade do trabalho coletivo e interdisciplinar que o PAEQUI mobiliza. Diferentes coordenações e bolsistas apoiadores dos mais variados cursos constituem um repertório de saberes e conhecimentos, trazendo elementos de dinamicidade e múltiplos olhares não apenas para as ações, mas para o desenvolvimento coletivo. Ao mesmo tempo em que contamos com 
esse aspecto positivo, a ausência de um bolsista apoiador de cada curso constituiu empecilho.

Assim, bolsistas apoiadores de áreas do conhecimento distintas acabaram por assumir responsabilidade pedagógica e de suporte a estudantes de cursos diferentes aos seus, o que nem sempre permitiu maior aproximação teórica, metodológica e didática. Neste sentido, um dos aspectos relevantes destacados nas reuniões de coordenação junto à PROEG era a ampliação do Programa e do número de bolsistas apoiadores, permitindo uma ação mais efetiva e adequada a cada área do conhecimento.

Tais espaços de debate e de concretização de ações que visem a melhoria da qualidade do ensino, a possibilidade de um percurso universitário distante do racismo e dos impactos desse nos estudantes, pautam, em parceria com a sociedade civil, a necessidade de uma universidade plural, inclusiva e articulada a saberes diversos, de distintas matrizes culturais e de produção de conhecimento.

Dentro desse viés, podemos considerar que a criação e a ampliação de PAA nas universidades também podem constituir ferramenta, instrumento capaz de oportunizar ao universo do chamado conhecimento científico, uma ampla gama de saberes outros, advindos dos mais distintos grupos dos quais nossos estudantes são originários, descendentes e/ou pertencentes. Nesse sentido, para além de políticas que viabilizem o acesso à universidade, faz-se fundamental a adoção de medidas e ações de permanência.

\section{Considerações Finais}

A Unifesspa tem seu surgimento articulado às demandas sociais, políticas e econômicas em contextos que envolvem diferentes movimentos de povos do campo, ribeirinhos, comunidades indígenas e quilombolas, movimentos negros, movimentos de mulheres, movimentos indígenas e outros tantos. Nesse sentido, pensar em políticas específicas de ações afirmativas constitui um debate que envolve a agenda da universidade, com propostas que atendam aos alunos em suas especificidades e diversidades, contribuindo para a transformação social da realidade envolvente.

Em termos de políticas de ação afirmativa conectada a preocupações sobre a permanência estudantil, o PAEQUI tem se constituído em espaço de diálogo entre docentes, estudantes apoiadores, estudantes atendidos e também a PROEG, Pró-reitoria responsável pelo Programa. Diante das experiências acumuladas ao longo de sete anos de existência da Unifesspa, as políticas de ação afirmativa passaram também por avaliações, 
atualizações e ampliações. Assim sendo, o PAEQUI, em sua versão 2018-2019, procurou articular ações em distintas perspectivas e também pensar no Programa enquanto uma política institucional, não apenas constituída por meio de editais que podem ou não ter renovação e alocação de recursos para viabilização.

Como apresentado ao longo do texto a experiência do PAEQUI (2018-2019), nos dois grupos da unidade III do campus de Marabá, mostrou que há a necessidade de uma pessoa na PROEG que possa assumir a coordenação das ações entre as coordenações de cada grupo de apoiadores nas vários campi e unidades da UNIFESSPA; necessidade de realizar a sistematização dos relatórios semestrais ou anuais de execução do projeto enviados à PROEG pelas coordenações e pelos(as) apoiadores(as), possibilitar a avaliação dos históricos de desempenho acadêmico dos alunos atendidos. Todas essas são ações necessárias para subsidiar o planejamento das atividades pelas coordenações de grupos de apoiadores e estreitar o diálogo com as coordenações de curso com vistas ao monitoramento constante da inserção dos estudantes quilombolas na vida acadêmica com vistas ao seu sucesso na instituição.

Além disso a realização de grupos de estudos, com encontros quinzenais, entre apoiadoras e coordenadoras dos dois grupos do PAEQUI, fomentou o conhecimento científico, a consciência política entre as bolsistas sobre racismos e a importância das ações afirmativas para pessoas negras (pretas e pardas) no Ensino Superior no Brasil.

\section{Referências}

ALMEIDA, Silvio L. de. Racismo estrutural. São Paulo: Pólen, 2019.

ASCOM/Unifesspa. Professora e alunos da Unifesspa participam do II Congresso Brasileiro de Pesquisadores Negros da região Norte. Disponível em: https://www.unifesspa.edu.br/index.php/component/content/article?id=3913. Acesso em:? 15 nov. 2020.

BRASIL, Congresso Nacional. Lei no 12.711, de 29 de agosto de 2012. Dispõe sobre o ingresso nas universidades federais e nas instituições federais de ensino técnico de nível médio e dá outras providências. Diário Oficial da União, Brasília, DF, 29 ago, 2012. Disponível em: http://www.planalto.gov.br/ccivil_03/_ato20112014/2012/lei/112711.htm. Acesso: 20 jan.2021.

CARVALHO, José Jorge. de. Los estudios culturales en América Latina: interculturalidad, acciones afirmativas y encuentro de saberes. Tabula Rasa. Bogotá Colombia, n..12, p. 229-251, enero-junio 2010. 
FERNANDES, Ana Paula de Souza; GUIDO, Claudina Gomes; SOARES, Irani Santos. Relatório do Seminário de Políticas Afirmativas e Diversidade da Unifesspa. Marabá: Unifesspa, 2016. Disponível em: <https:// proex.unifesspa.edu.br/images/conteudo/proex/Editais/Relatorio_Seminario_Acoes_Afi rmativas. Acesso em: 10 mar. 2018.

GOMES, Arilson dos S. Quilombolas e educação: vivências de ações afirmativas em três regiões brasileiras. MÉTIS: história \& cultura, v. 17, n. 33, p. 103-133, jan./jun. 2018.

HASENBALG, Carlos; SILVA, Nelson do Valle. Família, Cor e acesso escolar no Brasil. In: Cor e Estratificação Social. Rio de Janeiro. Contra Capa Livraria, 1999.

HENRIQUES, Ricardo. Desigualdade racial no Brasil: evolução das condições de vida na década de 90. Rio de Janeiro: Instituto de Pesquisa Econômica Aplicada, 2001. disponível em: Acesso em 20.10.2019

LEITE, Ilka. Boaventura. O projeto político quilombola: desafios, conquistas e impasses atuais. Estudos Feministas. Vol. 16, n. 3, 2008, p. 965-77.

SILVA, Paulo Vinicius Baptista da; TRIGO, Rosa Amália Espejo; MARÇAL, José Antonio. Movimentos negros e Direitos Humanos. In: NUNES, Georgina Helena; GOMES, Arilson dos Santos; BAPTISTA, Jean Tiago (Org.). I Copenesul - Congresso Regional de Pesquisadores Negros da Região Sul. Pelotas: Ed. da UFPel, 2015. p. 243 265.

MUNANGA, Kabengele. Políticas de Ação Afirmativa em benefício da população negra no Brasil: um ponto de vista em defesa de cotas. Sociedade e Cultura, v. 4, n. 2, jul./dez. 2001, p. 31-43.

Políticas de Ação Afirmativa em benefício da população negra no Brasil - um ponto de vista em defesa das cotas. In: SILVA, P. B. G.; SILVÉRIO, V. R. Educação e ações afirmativas: entre a injustiça simbólica e a injustiça econômica. Brasília: Inep, 2003, p. $115-130$.

PACHECO, Ana Julia; LIMA, Graziela dos Santos; CARDOSO, Paulino de Jesus Francisco. NÚCLEO DE ESTUDOS AFRO-BRASILEIROS (NEAB/UDESC): 10 anos de história. In: COELHO, W. B.; SANTANA, M.; CARDOSO, P. de J. F. (orgs.). $O$ Enfrentamento do Racismo e Preconceito no Brasil: a Experiência dos NEABs. Itajaí; Florianópolis: Casa Aberta; NEAB-UDESC, 2014, p. 29-53.

RASCKE, Karla Leandro et al. Formação para a Educação das Relações Étnico-Raciais: experiências em cursos de formação continuada - NEAB/UDESC. Revista Em Extensão, v. 13, n. 1, p. 9-19, 10 jul. 2014. . Anotações de Reunião com a PROEG. Marabá, 2019.

RIBEIRO, Djamila. Pequeno manual antirracista. São Paulo: Companhia das Letras, 2019. 
SANTOS, Antonio Bispo. (Nego Bispo). Colonização, quilombos, modos e significados. Brasília: CNPQ, $2015 . \quad$ Disponível em: cga.libertar.org/wpcontent/uploads/2017/07/BISPO-Antonio.-

Colonizacao_Quilombos.pdf?fbclid=IwAR1gYYWiTRxtcckaLuvpkLKPSxjLmvsoyNy urJgIoGg6Nlta-BRPkvy5Pmw. Acesso em: 15 mar. 2017.

SANTOS, Marcos Antonio Silva dos. Ações Afirmativas no Ensino Superior: Representações de Estudantes Quilombolas na UNIFESSPA. In: III CONEDU, 2016, Natal. Anais... Campina Grande: Realize Editora, 2016. (Anais Eletrônicos).

SILVA, Petronilha Beatriz Gonçalves e. Aprender, ensinar e relações étnico-raciais no Brasil. Revista Educação, Porto Alegre, v. 63, n. 3 (63), p. 489-506, set./dez. 2007.

Disponível em:

<http://revistaseletronicas.pucrs.br/ojs/index.php/faced/article/viewFile/2745/2092>.

Acesso em: 20 set. 2013.

UNIFESSPA. Pesquisa Diagnóstico: Programa de Acolhimento Estudantil \& Diversidade Indígenas e quilombolas na Unifesspa (2016). Universidade Federal do Sul e Sudeste do Pará, Marabá, Pará, 2017. prelo).

Plano de Desenvolvimento Institucional (PDI) 2020-2024. Marabá, 2020. (No

PORTARIA n. 1177/2020-UNIFESSPA. Institui a Comissão Permanente para Diversidade, Heteroidentificação e Etnicidade. 2012.

Artigo recebido em 01 de fevereiro de 2021. Aprovado em 14 de abril de 2021. 